\title{
Integrating ALN into an Independent Study Distance Education Program:
} NVCC Case Studies

\author{
John Sener \\ Northern Virginia Community College \\ Mary Liana Stover \\ University of Maryland University College
}

\begin{abstract}
This paper describes eight ALN courses developed under various Sloan Foundation-funded degree program initiatives at Northern Virginia Community College (NVCC) Extended Learning Institute (ELI). These chemistry, engineering, mathematics, and information technology courses offer useful lessons about what makes ALN courses successful. The courses incorporated ALN into an independent study format to increase interaction among learning participants while maximizing learner convenience and flexibility; some courses also focused on both on-line and in-person collaboration. A wide variety of other course design and delivery strategies contributed to the courses' success. The results of this study indicate that ALN courses can be viable and successful for community college students and that ALN can succeed in a distance education program delivered in an independent study format to motivated learners. NVCC/ELI's experience also suggests that ALN works within a multiple media approach to course design and delivery; that faculty selection, support, and development are critical factors in assuring quality ALN courses; that a wide variety of best practices can result in successful ALN courses; and that the learning effectiveness of ALN courses will continue to improve as better tools, content, and support are developed.
\end{abstract}

\section{INTRODUCTION}

\section{A. General Background}

This paper describes several ALN courses developed under various Sloan Foundation-funded degree program initiatives as described below. These particular courses were selected because each possesses unique or noteworthy characteristics (see Table 1) that offer useful lessons about what make ALN courses successful. One guiding assumption in selecting these courses was that, at least in our experience, when courses were less successful it was generally for prosaic and well-documented reasons, whereas courses which succeeded did so due to a variety of interesting and instructive factors. The following courses were selected as case studies:

\section{Case Study \#1: Chemistry}

College Chemistry I \& II (CHM 111/112) are four-credit courses designed primarily for science and engineering majors. These courses explore the fundamental laws, theories, and mathematical concepts of chemistry. CHM 111 is required for the Associate in Science (AS) Engineering degree. CHM 112 also was originally required for the AS Engineering degree program, but this requirement was dropped in 1996 when the degree program requirements were revised.

CHM 111 and 112 are of special interest because they attract a high percentage of students with prior degrees. Over $50 \%$ of the enrolled students have bachelor degrees and $12 \%$ have master's degrees and/or doctorates. Many of 
these students are self-described career changers who need a transfer chemistry course to pursue their new career goals in a diverse variety of fields such as medicine, engineering, physical therapy, and even enology.

\section{Case Study \#2: Engineering}

Introduction to Engineering (EGR 120) is a two-credit survey course which introduces the engineering profession so that students can determine whether engineering is a suitable field of study for them. EGR 120 is a required course for the AS engineering degree.

\section{Case Study \#3: Mathematics}

Vector Calculus (MTH 277); Differential Equations (MTH 291); Mathematics for the Liberal Arts I and II (MTH 151, 152). MTH 277 is a four-credit, second-year course on vector calculus. MTH 291 is a three-credit course on differential equations. MTH 151 and 152 are three-credit courses on basic mathematical concepts. MTH 151 fulfills the math requirements for a number of NVCC degree programs including the Associate in Applied Science (AAS) Information Systems Technology (IST) degree. MTH 152 is a requirement for the Associate in Arts (AA) Liberal Arts degree program and was developed to enable ELI to offer a complete AA Liberal Arts degree.

\section{Case Study \#4: Information Systems Technology}

Introduction to Internet Services (IST 128) is a three-credit course that provides students with a working knowledge of Internet terminology and services including E-mail, WWW browsing, search engines, ftp, telnet, and other services, as well as introducing students to related software packages and web page construction. IST 128 is an elective course for the AAS IST degree.

\begin{tabular}{|c|c|}
\hline Course & Noteworthy/Unique Characteristics \\
\hline CHM 111/112 & $\begin{array}{l}\text { Focus on collaboration, particularly face-to-face in lab settings } \\
\text { - Frequent/continuous improvement of course, including field-testing of technological } \\
\text { innovations in on-campus classes before incorporating them into ELI ALN courses } \\
\text { - Highly educated student population }(\sim 60 \% \text { with prior degrees })\end{array}$ \\
\hline EGR 120 & - Combined on-line, face-to-face collaboration in simulation assignment \\
\hline MTH 277/291 & $\begin{array}{l}\text { Innovative use of methods for two-way transmission of equations and graphical content } \\
\text { Innovative grading structure which rewards practice } \\
\text { - Continuous course improvement }\end{array}$ \\
\hline IST 128 & $\begin{array}{l}\text { Use of pre-packaged customizable course material within a Web course delivery program } \\
\text { (Serf) } \\
\text { - High volume of student/instructor interaction } \\
\text { - Large enrollments }\end{array}$ \\
\hline
\end{tabular}

Table 1: Noteworthy Characteristics of NVCC Case Study Courses

\section{B. The College}

NVCC is one of the three largest multi-campus community colleges in the United States and is the largest educational institution in Virginia. Founded in 1964, NVCC has grown rapidly so that in 1998-99, it enrolled 60,714 students (unduplicated headcount; 21,888 annualized FTEs). The college is comprised of five campuses and the ELI.

The ELI was established in 1975 as the College's distance learning administrative unit. It now has more than 11,000 enrollments per year (7,020 unduplicated headcount or $11.6 \%$ of the College's total) and offers more than 140 college credit courses delivered by a mix of cable and broadcast television, video and audiotapes, telephone, voice mail, print, World Wide Web, CD-ROM, and computer conferencing. From the beginning, ELI supported 
continuous enrollment in credit courses whereby students could enroll in classes at any point in the semester. Continuous enrollment and asynchronous learning continue to be at the heart of the ELI program.

ELI is organized as a home-study distance education unit. Geographic distance is not the barrier so much as distance through isolation caused by the students' hectic lives and difficulties of traveling even short distances in congested urban traffic. ELI primarily serves students whose busy lives and inability to get to campus preclude their participation in college courses.

Since 1991, ELI has received grant funding for three major development projects. With the first, through support from Annenberg/CPB's New Pathways to a Degree project, ELI developed Associates of Science (AS) degrees in Business Administration and General Studies for delivery at a distance. The second project, with grants from the Alfred P. Sloan Foundation, developed an AS degree in Engineering available using ALN through home-study distance education. The third project, still in process, is incorporating ALNs into the mainstream at NVCC as described below. The Alfred P. Sloan Foundation sponsors this program.

\section{The Programs}

From 1994-97, ELI developed the first and only AS in Engineering degree program available in the United States through ALN, funded by two grants from the Sloan Foundation. In fall 1997, ELI offered the complete engineering degree program, including 14 ALN courses in science, math, and engineering.

In 1998, Sloan funded a program to enable NVCC to scale-up its ALN course offerings. Through this program, 41 courses have been or will be developed using ALNs for distance as well as campus-based delivery. The program includes development of three degree programs and completion of a fourth degree program for distance delivery through ELI: Information Systems Technology, Microcomputer specialization (spring 2000), Business Management, Public Management specialization (spring 2000), Business Management without specialization (spring 2000), and Liberal Arts (fall 1999). The program also includes mini-grants to faculty for developing 21 ALN courses or course components in on-campus and ELI courses.

\section{Intended Audience}

The intended audience for the ALN programs is community college students who are employed or have significant outside responsibilities and find that time and location are major obstacles to attaining degrees. The intended students are those requiring flexibility to complete a degree program. Compared to their colleagues in campus-based courses, these students tend to work more hours at outside employment, have more family responsibilities, and in general have less uninterrupted time, especially during regular business hours, to dedicate to their college studies. The students are slightly older than on-campus students with $46 \%$ of them being $25-44$ years old. About $70 \%$ are part-time students and $60 \%$ are women. Usually about $50 \%$ of ELI students take ELI courses only, and the other half take both ELI and campus courses.

While ELI students value the flexibility and convenience of self-paced, independent study, most learners live within 20 miles of one of NVCC's five campuses. ELI students are thus generally able to visit a campus occasionally for exams, laboratory exercises, or other course-related activities. Because of the proximity of students, ELI has supported computer-mediated communication software such as Searchlight (1990-95), Lotus Notes (1994-95), and FirstClass (1995-99) that allows access with a local phone call. ELI now supports Web-based conferencing, using Allaire Forums, Web-Course-in-a Box, and Blackboard/Course Info now that Internet access is widespread.

\section{RATIONALE}

\section{A. Motivating Factors for Program Development}

ELI and NVCC's engineering faculty initiated the engineering degree ALN program funded by the Sloan Foundation. The program addressed the problem facing potential engineers enrolled in transfer-oriented degree programs of how to complete a degree program when encumbered with many professional and family obligations. 
The engineering degree program was also developed as a proof of concept project funded by Sloan to determine the feasibility of offering home-study, distance-education ALN courses in these subject areas.

The second ALN project supported by the Sloan Foundation was designed to bring ALNs into the mainstream at NVCC through a large-scale deployment of ALN courses and degree programs in key disciplines. The project is intended to address the need in Northern Virginia to have educational opportunities which are accessible anywhere, anytime for the growing new majority of students who face significant obstacles preventing them from attaining degrees via traditional on-campus classes. The project also addresses the critical shortage of information technology (IT) workers in Northern Virginia and the resulting high demand for IT courses at the College, as well as the need in Northern Virginia for education and training opportunities relevant to public sector employment.

The ELI was one of the few institutions using distance ALNs before the Sloan Foundation initiatives, so the ALN projects fit neatly into ELI's existing structure. In fall 1989, ELI introduced the use of computer conferencing on the mainframe computer for use in instruction. Voice-mail conferencing was introduced in 1993. With the Sloan grants, computer conferencing on personal computers using a bulletin board system began in 1995. The first courses delivered via the World Wide Web were offered in 1998.

\section{B. Evaluation Methods}

Originally, planned evaluation activities included formative and summative evaluations. Planned formative evaluation consisted of

- Focus group meetings of students to get feedback on the effectiveness of pilot courses

- Faculty and student surveys on the effectiveness of courses, technologies, and procedures

- Grade distribution studies to determine rates of student success

Planned summative evaluation consisted of

- Faculty and student surveys on the effectiveness of courses, technologies, and procedures

- Grade distribution studies to determine rates of student success

- Telephone interviews with students to determine their satisfaction with the courses

- Interviews with faculty, staff, and administrators on project outcomes

- If possible, a tracking study to determine graduation and transfer rates for students who take a majority of the program by distance education

The original evaluation plan was intentionally short on details so that suitable evaluation activities could be developed as the project progressed. Various evaluation methods were employed during the project periods; those related to learning effectiveness are described in the Results section below.

\section{BACKGROUND INFORMATION FOR THE NVCC CASE STUDY COURSES}

The students served in the engineering project are fairly similar to engineering students enrolled in on-campus courses. However, as in other distance programs, the students are slightly older and more often employed full-time than those in on-campus programs. Since its development, the ELI engineering degree has had over 1,300 total enrollments. Program enrollments declined slightly after peaking in fall 1997 and now number more than 300 per academic year. Comparative analyses show that students who start their courses have achieved success rates comparable to their on-campus counterparts. 
The courses discussed in the case studies have been offered a varying number of times (see Table 2). CHM 111 and EGR 120 were first offered in spring 1995 and have been taught most semesters since then. MTH 152 is the most recently developed of the case study courses and was taught for the first time in summer 1999.

\begin{tabular}{|c|c|c|c|c|c|c|c|c|}
\hline & CHM 111 & $\begin{array}{c}\text { CHM } \\
112\end{array}$ & EGR 120 & MTH 277 & MTH 291 & MTH 151 & $\begin{array}{c}\text { MTH } \\
152\end{array}$ & IST 128 \\
\hline $\begin{array}{l}\text { Total \# of } \\
\text { Times Offered }\end{array}$ & 8 & 3 & 8 & 10 & 8 & 2 & 1 & 5 \\
\hline \multicolumn{9}{|l|}{ Enrollments: } \\
\hline Spring 1995 & 31 & & 15 & & & & & \\
\hline Spring 1996 & 26 & & 23 & & & & & \\
\hline Summer 1996 & & & & 15 & & & & \\
\hline Fall 1996 & 27 & & 21 & 8 & 14 & & & \\
\hline Spring 1997 & 34 & & 19 & 11 & 13 & & & \\
\hline Summer 1997 & & & & 13 & & & & \\
\hline Fall 1997 & 21 & 12 & 26 & 15 & 13 & & & \\
\hline Spring 1998 & 14 & 8 & 18 & 9 & 9 & & & 8 \\
\hline Summer 1998 & & & & 9 & 13 & & & 37 \\
\hline Fall 1998 & 24 & & 16 & 12 & 7 & & & 63 \\
\hline Spring 1999 & 21 & 6 & 18 & 9 & 4 & 62 & & 88 \\
\hline Summer 1999 & & & & 13 & 23 & 46 & 20 & 38 \\
\hline $\begin{array}{l}\text { Total } \\
\text { Enrollments: }\end{array}$ & 196 & 26 & 156 & 114 & 96 & 108 & 20 & 234 \\
\hline
\end{tabular}

Table 2. Frequency of Offerings \& Enrollments by Semester, NVCC Case Study Courses

\section{METHOD}

\section{A. Technology and Infrastructure}

As described below, computer technology was used primarily to facilitate interaction among learning participants and only secondarily for content delivery in some courses. College Chemistry I and Introduction to Engineering were two of the first courses developed as part of Sloan's initial grant to NVCC/ELI. For the first iteration of these courses, Lotus Notes v4.13 was used as the course development and management system. This was before Lotus's development of Lotus LearningSpace. Although Lotus Notes was a powerful system with many useful features, Lotus Notes was replaced with FirstClass (with Internet access) in the spring 1996 semester as an alternative that would be easier to use and administer, less expensive for the institution and students, and equal to Notes for instructional purposes [1]. FirstClass was subsequently used for the College Chemistry II, Vector Calculus, Differential Equations, and Introduction to Engineering courses. ELI managed technical infrastructure in-house. Consulting services were used in the initial installation and implementation of FirstClass, but operation and maintenance proved to be sufficiently simple that no additional consulting services were used even though funds were set aside for that purpose. As E-mail has become more widely available at the College and for its students, the advantages of using FirstClass have diminished. Accordingly, all case-study courses that are still using FirstClass are being migrated to a Web-based conferencing system (Allaire Forums) as of the fall 1999 semester. 


\section{B. Content Delivery}

In the early and mid-1990s when most of these courses were developed, ELI utilized a multiple media approach to course development. The earlier courses were designed with a specific model in mind: video and print media for content delivery, computer conferencing and telephone for interaction facilitation. When computer conferencing was used for content delivery, it was only as a supplementary means, for example, homework help, questions and answers, or assignment transmission. By contrast, the courses developed in the past two years utilize the Web as the principal delivery medium along with selected course delivery management tools and other software as described below. In addition, the use of various methods and media evolved in different ways in different courses over time. Table 3 summarizes the use of media in the case-study courses by semester.

Most ELI courses feature self-paced, independent study as well as continuous enrollment, which allow students to register for most ELI courses on virtually any day of the year. However, for most of these courses, continuous enrollment was suspended to enable face-to-face activities and other forms of cohort formation to facilitate collaborative learning activities. For the mathematics courses, however, as it became apparent that learning participants were most comfortable with instructor-student interaction and cohort formation was unnecessary, continuous enrollment was re-instituted.

Several noteworthy content delivery strategies were employed in the case-study courses. For the chemistry courses, technological innovations were field-tested in the classroom before incorporating them into the ELI ALN courses. For instance, the instructor field-tested the use of ChemSkillBuilder ${ }^{T M}$ electronic homework exercises on campus in spring 1998, then incorporated them into the ELI ALN course in fall 1998. Similarly, the use of CD-ROM material bundled with a revised edition of the course textbook was piloted on-campus in spring 1999 and was incorporated into the ELI ALN course in the fall 1999 semester.

Face-to-face meetings were required for the Introduction to Engineering (EGR 120) and chemistry courses. The EGR 120 course required one face-to-face meeting designed as a culminating activity for an on-line collaborative learning assignment. The assignment required students to conduct a mock technical meeting of a fictitious engineering company dealing with an engineering-related manufacturing problem. The chemistry courses required two-to-five, face-to-face meetings to conduct laboratory experiments. The laboratories were self-contained activities in the College Chemistry II course; however, in the College Chemistry I course, students were required to work collaboratively to prepare pre- and post-lab reports.

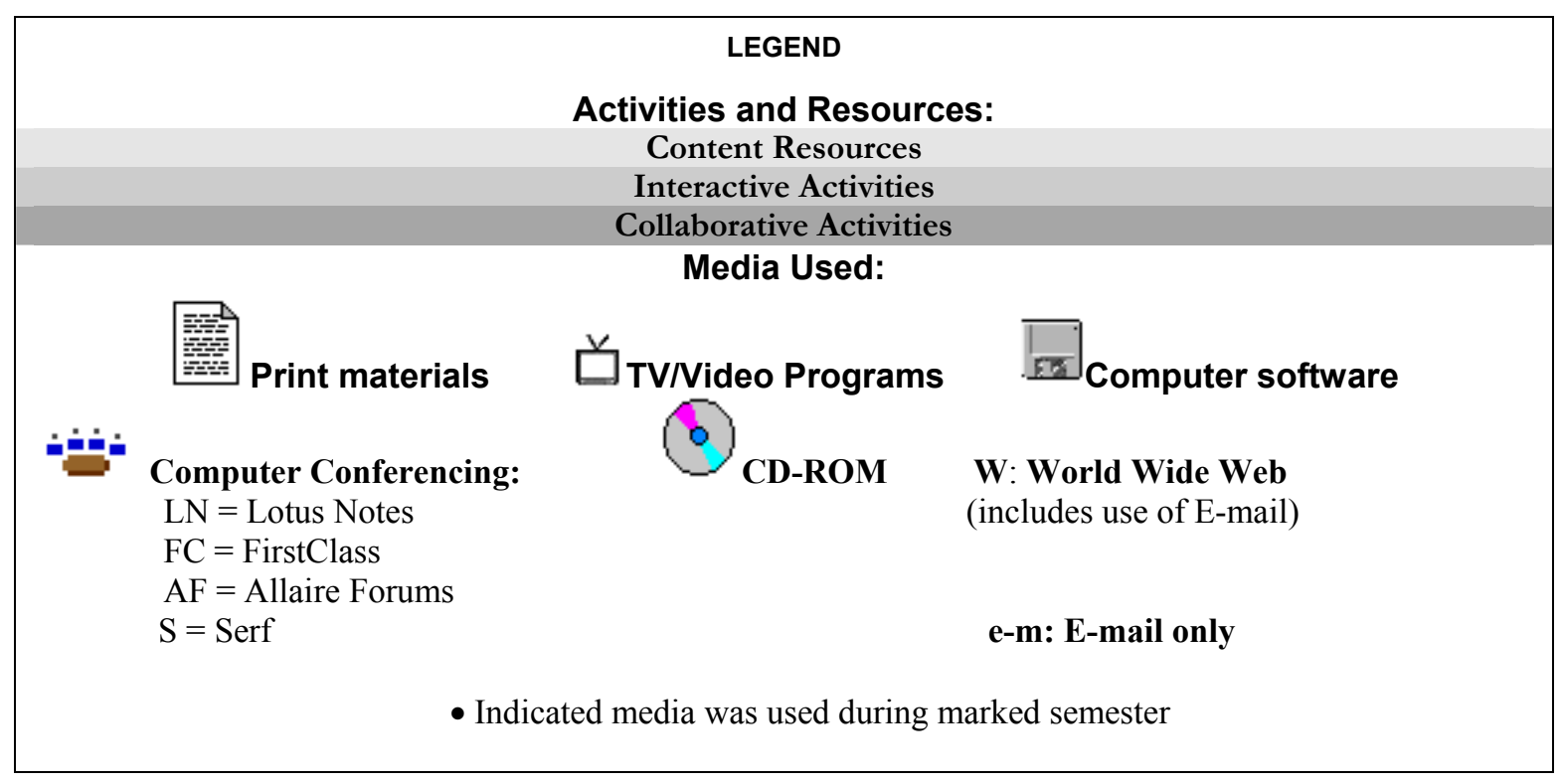




\begin{tabular}{|c|c|c|c|c|c|c|c|c|c|c|c|c|c|c|}
\hline \multirow{2}{*}{ Activities/ Resources } & \multirow[b]{2}{*}{ Media } & \multirow{2}{*}{$\begin{array}{l}1995 \\
\mathrm{Sp}\end{array}$} & \multicolumn{3}{|c|}{1996} & \multicolumn{3}{|c|}{1997} & \multicolumn{3}{|c|}{1998} & \multicolumn{3}{|c|}{1999} \\
\hline & & & $S p$ & Sm & $\mathbf{F}$ & Sp & Sm & $F$ & Sp & $\mathrm{Sm}$ & $F$ & Sp & Sm & $F$ \\
\hline \multicolumn{15}{|l|}{ All Courses } \\
\hline Syllabus & & • & $\bullet$ & • & $\bullet$ & • & • & • & • & • & $\bullet$ & • & $\bullet$ & $\bullet$ \\
\hline Course guide & & - & • & • & $\bullet$ & - & $\bullet$ & • & • & • & - & - & - & - \\
\hline Textbook(s) & & - & $\bullet$ & $\bullet$ & • & - & $\bullet$ & $\bullet$ & $\bullet$ & $\bullet$ & $\bullet$ & - & $\bullet$ & - \\
\hline $\begin{array}{l}\text {Q\&A - private E-mail } \\
Q \& A \text { - conference }\end{array}$ & 的 & $\bullet$ & $\bullet$ & $\bullet$ & $\bullet$ & $\bullet$ & $\bullet$ & $\bullet$ & $\bullet$ & $\bullet$ & $\bullet$ & $\bullet$ & $\bullet$ & $\bullet$ \\
\hline \multicolumn{15}{|l|}{ CHM $111 / 112^{1}$} \\
\hline $\begin{array}{l}\text { Lecture material } \\
\text { Laboratory guide }\end{array}$ & 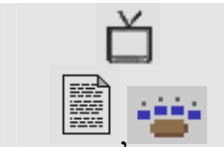 & $\bullet$ & • & & $\bullet$ & $\bullet$ & & $\bullet$ & $\bullet$ & & $\bullet$ & $\bullet$ & & - \\
\hline $\begin{array}{l}\text { (HW Help/e-lectures) } \\
\text { Homework assignments }\end{array}$ & & $\mathrm{LN}$ & $\begin{array}{l}\mathrm{F} \\
\mathrm{C}\end{array}$ & & $\mathrm{FC}$ & FC & & $\mathrm{FC}$ & $\mathrm{FC}$ & & $\begin{array}{l}\mathrm{FC} \\
\bullet\end{array}$ & $\begin{array}{l}\mathrm{FC} \\
\bullet\end{array}$ & & AF \\
\hline Student introductions & غ亡غ & $\mathrm{LN}$ & $\begin{array}{l}\mathrm{F} \\
\mathrm{C}\end{array}$ & & $\mathrm{FC}$ & $\mathrm{FC}$ & & FC & $\mathrm{FC}$ & & $\mathrm{FC}$ & $\mathrm{FC}$ & & $\mathrm{AF}$ \\
\hline $\begin{array}{l}\text { Lab experiments, } \\
\text { Lab reports }\end{array}$ & 至 & $\mathrm{LN}$ & $\begin{array}{l}\mathrm{F} \\
\mathrm{C}\end{array}$ & & $\mathrm{FC}$ & $\mathrm{FC}$ & & $\mathrm{FC}$ & $\mathrm{FC}$ & & $\mathrm{FC}$ & $\mathrm{FC}$ & & $\mathrm{AF}$ \\
\hline \multicolumn{15}{|l|}{ EGR 120} \\
\hline Lecture material & 占, 音 & 口 & $\begin{array}{l}\mathrm{F} \\
\mathrm{C}\end{array}$ & & $\mathrm{FC}$ & $\mathrm{FC}$ & & $\mathrm{FC}$ & $\mathrm{FC}$ & & $\mathrm{FC}$ & $\mathrm{FC}$ & & $\mathrm{AF}$ \\
\hline $\begin{array}{l}\text { Library research } \\
\text { Computer program }\end{array}$ & 的音 & & $\begin{array}{l}\mathrm{F} \\
\mathrm{C}\end{array}$ & & FC & FC & & FC & $\mathrm{FC}$ & & FC & FC & & $\mathrm{AF}$ \\
\hline (Student introductions) & ت咅 & & & & & & & & & & & & & \\
\hline Mock meeting & F2F & & - & & • & $\bullet$ & & - & - & & $\bullet$ & $\bullet$ & & $\bullet$ \\
\hline \multicolumn{15}{|l|}{ MTH $277 / 291^{2}$} \\
\hline $\begin{array}{l}\text { Lecture material } \\
\text { Practical applications } \\
\text { (Q\&A), (Mini-lectures) }\end{array}$ & 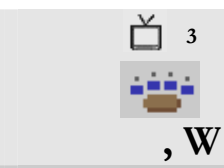 & & & $\begin{array}{l}\bullet \\
\mathrm{FC} \\
\mathrm{FC}\end{array}$ & $\begin{array}{l}\bullet \\
\text { FC } \\
\text { FC }\end{array}$ & $\begin{array}{l}\bullet \\
\mathrm{FC}\end{array}$ & $\begin{array}{c}\bullet \\
\mathrm{FC}\end{array}$ & $\begin{array}{l}\bullet \\
\mathrm{FC}\end{array}$ & $\begin{array}{c}\bullet \\
\text { FC }\end{array}$ & $\begin{array}{c}\bullet \\
\text { FC }\end{array}$ & $\bullet$ & FC & $\begin{array}{l}\bullet \\
\text { FC }\end{array}$ & - \\
\hline $\begin{array}{l}\text { Practical applications } \\
\text { Quizzes } \\
\text { (Q\&A), (Mini-lectures) }\end{array}$ & ,W & & & $\begin{array}{l}\text { FC } \\
\text { FC }\end{array}$ & $\begin{array}{l}\text { FC } \\
\text { FC }\end{array}$ & $\begin{array}{l}\text { FC } \\
\text { FC }\end{array}$ & $\begin{array}{l}\text { FC } \\
\text { FC }\end{array}$ & $\begin{array}{l}\text { FC } \\
\text { FC }\end{array}$ & $\begin{array}{l}\text { FC } \\
\text { FC }\end{array}$ & $\begin{array}{l}\text { FC } \\
\text { FC }\end{array}$ & $\begin{array}{l}\text { FC } \\
\text { FC }\end{array}$ & $\begin{array}{l}\text { FC } \\
\text { FC }\end{array}$ & $\begin{array}{l}\text { FC } \\
\text { FC }\end{array}$ & $\begin{array}{l}\text { e-m } \\
\text { W }\end{array}$ \\
\hline \multicolumn{15}{|l|}{ MTH 151/152 } \\
\hline (Q\&A), (Mini-lectures) & $\mathbf{W}, \square$ & & & & & & & & & & & $\bullet$ & $\bullet$ & $\bullet$ \\
\hline $\begin{array}{l}\text { Quizzes } \\
\text { (Q\&A), (Mini-lectures) }\end{array}$ & $\mathbf{W}$, & & & & & & & & & & & $\bullet$ & $\bullet$ & $\bullet$ \\
\hline \multicolumn{15}{|l|}{ IST 128} \\
\hline $\begin{array}{l}\text { Lecture material } \\
\text { Homework assignments }\end{array}$ & $\mathrm{W}$, 咅 & & & & & & & & $\begin{array}{l}S \\
S\end{array}$ & $\begin{array}{l}S \\
S\end{array}$ & $\begin{array}{l}S \\
S\end{array}$ & $\begin{array}{l}S \\
S\end{array}$ & $\begin{array}{l}S \\
S\end{array}$ & $\begin{array}{l}S \\
S\end{array}$ \\
\hline Homework assignments & $\mathrm{W}$, & & & & & & & & S & S & $S$ & S & S & S \\
\hline
\end{tabular}


Table 3. ALN Activities, Resources and Media in NVCC Case Study Courses by Semester

The more recently developed courses use the World Wide Web in different ways to deliver content. The Mathematics for the Liberal Arts I and II courses (MTH 151/152) use instructor-developed pages rather than a commercial course management system. The Introduction to Internet Services course (IST 128) uses a pre-packaged course, Internet Literacy, which operates within a Web course delivery program (Serf), both of which were developed at the University of Delaware and licensed through the Public Broadcasting Service (PBS). In the spring 1999 semester, this content was customized by the IST 128 instructor to make the course more specific to its student population.

One noteworthy challenge related to content delivery involved how to facilitate affordable, two-way transmission of equations, formulas, and graphical content. Although software such as Mathematica and Maple V were available at the time, they were far too expensive to be considered for use by home-study, community college students. Instead, a solution was developed which used an equation typesetter product called Expressionist which, used with FirstClass, provided an affordable means $(<\$ 2 /$ student) for students to compose and transmit documents with equations, formulas, etc. This solution proved to be serviceable in the mathematics courses for several semesters [2] until a better solution was identified, which was incorporated into the Mathematics for the Liberal Arts courses. These courses use Scientific Notebook as the means of mathematical communication with students. The instructor and students use the software to transmit quizzes, homework problems, and general questions and answers to each other. The instructor arranged for the textbook publisher to bundle Scientific Notebook with the course textbook at a greatly reduced rate ( $\$ 29.95$ vs. $\$ 75$ retail). Besides its equation-editor capability, Scientific Notebook also contains the Maple ${ }^{\mathrm{TM}}$ symbolic engine for computational power; Scientific Notebook also has one of the easiest user interfaces of the available math software packages. The instructor currently uses MSWord with MathType, the full version of the Equation Editor that comes with Word to post Web pages with mathematical content [3]. This procedure is much easier and quicker to download than the previous common practice of embedding mathematical expressions within graphics on Web pages.

Student performance was assessed in a variety of means (see Table 4). Tests and quizzes were conducted in the same manner as with all ELI courses; students were required to take exams at a testing lab at one of NVCC's five campuses. Students outside the NVCC service area could arrange for local exam proctoring as necessary in accordance with ELI's existing procedures. Of special interest is how quizzes were conducted in the mathematics courses. After studying the related material, students requested a quiz, which was sent to them via E-mail. The student used Scientific Notebook to complete the quiz and then returned it to the instructor. The quizzes were graded excellent, satisfactory, or unsatisfactory; however, the student received full credit for submitting the completed quiz, regardless of the grade. Since the ten required quizzes collectively comprised $25 \%$ of the course grades, students, in effect, were rewarded for effort rather than punished for practice, while the instructor received valuable feedback on student progress, which was used to monitor and improve student performance.

\begin{tabular}{|c|c|c|}
\hline Course & Graded Assignments & Special Requirements \\
\hline CHM 111 & $\begin{array}{l}3 \text { exams } \\
1 \text { comprehensive final exam } \\
10 \text { homework assignments } \\
10 \text { laboratory exercises } \\
\text { (4-8 off-campus; } 2-6 \text { on-campus) }\end{array}$ & $\begin{array}{l}\text { Introductory letter and course completion } \\
\text { plan; passing grades }(\geq 60 \%) \text { in both lab and } \\
\text { 'lecture' course components }\end{array}$ \\
\hline CHM 112 & $\begin{array}{l}3 \text { exams } \\
1 \text { comprehensive final exam } \\
6 \text { homework assignments } \\
6 \text { laboratory exercises } \\
\text { ( } 3 \text { off-campus; } 3 \text { on-campus) }\end{array}$ & $\begin{array}{l}\text { Introductory letter and course completion } \\
\text { plan; passing grades }(\geq 60 \%) \text { in both lab and } \\
\text { 'lecture' course components }\end{array}$ \\
\hline
\end{tabular}




\begin{tabular}{|l|l|l|}
\hline \multirow{2}{*}{ EGR 120 } & $\begin{array}{l}4 \text { exams } \\
1 \text { library research paper } \\
1 \text { computer program } \\
1 \text { mock engineering meeting }\end{array}$ & $\begin{array}{l}\text { Lowest grade is discarded in calculating final } \\
\text { grade }\end{array}$ \\
\hline $\begin{array}{l}\text { MTH 277, 291, } \\
\mathbf{1 5 1 , 1 5 2}\end{array}$ & $\begin{array}{l}1 \text { midterm } \\
1 \text { final }\end{array}$ & $\begin{array}{l}\text { Quizzes are graded excellent, satisfactory, or } \\
\text { unsatisfactory; credit given for completion, } \\
\text { not performance }\end{array}$ \\
\hline \multirow{2}{*}{$\mathbf{1 S T} \mathbf{1 2 8}$} & 3 quizzes & $\begin{array}{l}\text { All assignments except quizzes submitted via } \\
\text { Internet }\end{array}$ \\
& 1 home page \& resume \\
& 1 term paper & \\
\hline
\end{tabular}

Table 4. Student Performance Assessment in NVCC Case Study Courses

\section{Organization and Evolution 1. Course Development}

ELI uses a faculty-centered course development model in which faculty members and instructional technologists collaborate to develop course materials for delivery. Faculty serve as content experts and are highly involved in developing and teaching their own courses. Instructional technologists provide instructional design expertise. The engineering degree courses were developed by teams, each composed of a faculty member, instructional technologist, a video producer (when applicable), and clerical support staff [4]. Other staff instructional technologists were employed as consultants on an as-needed basis.

\section{Technical Support}

ELI staff instructional technologists provide technical support for course development and delivery. Instructional technologists train faculty in the instructional use of technology and provide technical support during the course development process. ELI instructional technologists also provide course delivery technical support, including trouble shooting for students and faculty and server administration. Front-line clerical staff answer basic technical questions from students and refer other questions to ELI instructional technologists.

\section{Course Development Budget}

Course development funds were provided by grants from the Sloan Foundation. The course development costs for the engineering degree courses and the more recently developed courses differ markedly. This differential is due to several factors:

- Large decreases in software costs during the project development period

- Pre-existing software infrastructure for more recently developed courses

- Video production expenses for the engineering degree courses (except MTH 291)

- The pioneering nature of the engineering degree program

Although costs per course are difficult to quantify with precision since some costs (e.g., software) are not allocated per course, the figures in Table 5 represent reasonable estimates. Note that the figures in Table 5 do not include recurring course delivery costs. Although in most cases these costs are low, the IST 128 course incurs about \$2$4,000 /$ year in costs due to licensing and student fees. 


\begin{tabular}{|l|l|l|l|}
\hline Course & Development Period & Development Costs & Comments \\
\hline Engineering degree courses: & Course redeveloped in second project phase \\
\hline CHM 111 & $\begin{array}{l}\text { Fall '94; Summer/Fall } \\
\text { '95 }\end{array}$ & $\$ 16,100^{*}$ & \\
\hline CHM 112 & Summer/Fall '97 & $\$ 16,100^{*}$ & Course redeveloped in second project phase \\
\hline EGR 120 & $\begin{array}{l}\text { Fall '94; Summer/Fall } \\
\text { '95 }\end{array}$ & $\$ 12,700^{*}$ & \\
\hline MTH 277 & Fall '95/Spring '96 & $\$ 14,300^{*}$ & \\
\hline MTH 291 & Spring/Summer '96 & $\$ 8,100$ & \\
\hline Other courses: & Summer/Fall '98 & $\$ 4,000$ & Web-based course \\
\hline MTH 151 & Spring '99 & $\$ 4,000$ & Web-based course \\
\hline MTH 152 & $\begin{array}{l}\text { Spring'98; } \\
\text { Spring '99 }\end{array}$ & $\$ 3,000$ & $\begin{array}{l}\text { Web-based course; course redeveloped for } \\
\text { IST 128 }\end{array}$ \\
\hline *Includes video production and videotape distribution costs & \\
\hline
\end{tabular}

Table 5. Development Costs for NVCC Case Study Courses

\section{RESULTS}

Overall, the case study courses have been successful both compared to other ELI courses and to their on-campus counterparts. Although comparisons have not been done for each individual case-study course, extensive evaluation activities performed on the Engineering degree program as a whole indicated that students who started Engineering degree program courses were roughly as successful as their on-campus counterparts [5].

\section{A. Faculty Perceptions of Learning Effectiveness}

As indicated in Tables 6 and 7 below, according to the case-study faculty this success is attributable to a variety of course design and student-related factors. The factors cited by faculty as necessary for student success (see Table 7) are not surprising, as they are in line with ELI's past experience with home-study, distance education learners. This is reflected for instance in ELI's "Is ELI for Me?" questionnaire, a ten-question, self-administered student survey designed to allow students to assess whether distance learning is suitable for them. The questionnaire contains similar questions about personal preferences for interaction, need for course, reading ability, etc. This questionnaire has been widely adopted and distributed in various forms throughout higher educational institutions in the U.S.

\begin{tabular}{|l|l|l|l|l|}
\hline & CHM 111/112 & EGR 120 & MTH 277/291 & IST 128 \\
\hline Good analytical ability & $\mathrm{x}$ & & & \\
\hline Takes responsibility, is accountable & $\mathrm{x}$ & & & \\
\hline Self-motivated & & $\mathrm{x}$ & & $\mathrm{x}$ \\
\hline Doesn't need/want student-student interaction & & $\mathrm{x}$ & & $\mathrm{x}$ \\
\hline "Good student" & & & $\mathrm{x}$ & \\
\hline Willing to ask questions & & & $\mathrm{x}$ & $\mathrm{x}$ \\
\hline Doesn't have external problems & & & $\mathrm{x}$ & \\
\hline Self-disciplined & & & & $\mathrm{x}$ \\
\hline Good reading comprehension & & & $\mathrm{x}$ & $\mathrm{x}$ \\
\hline Has adequate prior knowledge base/preparation & & & & $\mathrm{x}$ \\
\hline Good writing skills & & & $\mathrm{no}$ & $\mathrm{no}$ \\
\hline Mature, age a factor & $\mathrm{x}$ & & \\
\hline
\end{tabular}

Table 6. Which Students Are Best-Suited for ELI ALN Courses? Success Factors Cited by NVCC Case Study Faculty 


\begin{tabular}{|c|c|c|c|c|}
\hline & CHM 111/112 & $\begin{array}{c}\text { EGR } \\
120\end{array}$ & $\begin{array}{c}\text { MTH } \\
277 / 291\end{array}$ & $\begin{array}{l}\text { IST } \\
128\end{array}$ \\
\hline \multicolumn{5}{|l|}{ Pedagogies which worked well (+) or inadequately (-): } \\
\hline Using "student-directed tools" & + & & & \\
\hline Face-to-face interaction preceding on-line interaction & + & & & \\
\hline Face-to-face interaction following on-line collaboration & & $+/-$ & & \\
\hline Collaborative learning w/appropriate preparation & + & & & \\
\hline Using quizzes for practice performance $\mathrm{w} /$ feedback & & & + & \\
\hline Resubmission of substandard assignments & & & & + \\
\hline One-to-one student/instructor communication & + & + & & + \\
\hline \multicolumn{5}{|l|}{ Media which worked well $(+)$ or inadequately (-): } \\
\hline Computer conferencing & + & + & & + \\
\hline Expressionist/FirstClass for 2-way math transmission & & & $+/(-)$ & \\
\hline 'Electronic homework' (ChemSkillBuilder software) & + & & & \\
\hline Videotapes & + & - & & \\
\hline World Wide Web/E-mail & & & & + \\
\hline Print content delivery & $+/-$ & + & & \\
\hline Telephone & "unnecessary" & & & \\
\hline
\end{tabular}

Table 7. Course Design Features Cited by NVCC Case Study Faculty as Critical Factors for Successful Course Performance for ELI ALN Courses

The case-study course instructors cited a variety of pedagogical and technological factors that were critical for student success and learning effectiveness in their courses, as summarized in Table 7 above.

\section{Chemistry (CHM 111/112)}

Both instructors who developed the course were strong believers in incorporating collaborative activities into the learning process whenever feasible. They believed that collaborative learning worked best with appropriate preparation, including didactic instruction, and with appropriate guidance from the instructor. However, one instructor noted a distinct difference in the quality of her on-line communication with students after the first face-toface laboratory session. Her experience was that having several on-campus lab sessions resulted in a more productive learning environment, produced more collaboration, a sense of camaraderie, and resulted in more productive on-line interactions than would occur if there were fewer on-campus laboratory sessions. Face-to-face sessions were also best for enabling certain kinds of hands-on lab experience.

Technologies that worked well for the chemistry students were student-directed tools, including computer conferencing, interactive CD-ROM, electronic homework software (ChemSkillBuilder), and videotapes. Videotapes and print materials (and to a lesser extent computer conferencing) worked well to deliver most of the course content involving fundamental principles and concepts of chemistry with examples and demonstrations, while the ChemSkillBuilder software effectively enabled skills practice. The instructor also found that telephone communication was not particularly effective, since on-line and face-to-face communication made the telephone unnecessary.

\section{Introduction to Engineering (EGR 120)}

Unlike the chemistry courses, in the introductory engineering course most of the on-line interaction and collaboration among students preceded rather than followed the face-to-face meeting. The instructor felt that the success of this on-line collaboration was largely dependent on the number of enrolled students and their particular characteristics. The on-line collaborative assignments did not work well when roughly fewer than about a dozen students participated in it. Also, some students responded well to on-line collaboration, and others did not; in fact, some students did not like the face-to-face meeting assignment because even one required in-person visit impeded the flexibility and convenience of taking the course. Accordingly, on-line collaboration was usually, though not always, successful. 


\section{Mathematics (MTH 277/291)}

As described previously, the use of quizzes to enable students to practice performance without punishment has proved to be an effective means for the instructor to provide feedback and monitor progress more frequently. Improvements in the enabling technologies have increased the ease and convenience of this interaction. The instructor noted that the initial enabling technology used (Expressionist + FirstClass) was a definite improvement over paper and pencil. However, Scientific Notebook also represented a definite improvement over Expressionist + FirstClass because it is a more convenient equation editor and a more powerful math tool which enables students to focus on the problem-solving process. Scientific Notebook can also be used for many math courses. Similarly, the instructor has found the Web to be better than the FirstClass client environment because it has more flexible space, fewer constraints, and is more accessible since it is easier to install and use. The instructor also noted that all of math content in his calculus and liberal arts math courses is suitable for delivery via the Web, although he speculated that dealing with discrete math proofs could be a problem.

\section{Introduction to Internet Services (IST 128)}

The instructor noted several minor technological and pedagogical aspects that impeded learning effectiveness. There was too much written text on the screen; the course materials were so densely hyper-linked that it was virtually impossible for students to print it out; some of the category labels within Serf were non-intuitive and difficult for students to figure out; and access to the Serf Website was often slow and occasionally unavailable. However, the instructor also felt that the advantages of using Serf and the on-line Internet Literacy course outweighed the disadvantages. Having pre-organized publisher resources was much more efficient and timesaving for both students and instructor. Using customizable pre-packaged course material allowed the instructor to adapt the existing course material to students' needs. Another development noted by the instructor was a tendency toward supporting a more mastery learning-oriented approach to assessment by allowing students to resubmit substandard assignments (not including exams). The instructor's experience was that, by having a well-organized structure and supporting rapid feedback, the technology made this much easier to do, unlike on-campus courses where such an approach was impractical.

These features not only facilitated learning effectiveness but also increased the instructor's capacity to teach larger numbers of students effectively. They also encouraged a much greater volume of student/instructor interaction. Although exact figures were not available, the instructor estimated that she had at least ten times as many one-onone interactions with students in her ELI ALN course than with students in her on-campus courses. Another subjective but perhaps telling indicator of the success of one-on-one interaction is that several students who had never met the instructor face-to-face while taking the course came to visit the instructor at ELI's semester orientation—after they had already completed the course.

Several common themes emerged from the case-study courses. One of them was that ELI students often seemed to learn more in-depth than students in on-campus courses. In the chemistry courses, this was attributed in part to the ELI classes having a much higher percentage of excellent students, at times "just extraordinary". The IST 128 instructor felt that students learned more and received better grades because she was able to "hold [her students'] feet to the fire more" than was possible in an on-campus class. Another possible explanation is the fact that homestudy courses such as ELI's do not allow instructors to skimp on content covered in the latter stages of a course due to time constraints.

Another commonly mentioned factor to consider was the variation in course performance from semester to semester within the same course. Just as with on-campus courses, this is probably more a function of the particular collection of students enrolled in a course in a given semester than a function of the courses themselves. This is a factor worth considering when assessing learning effectiveness in ALN courses, especially in comparison to on-campus courses.

\section{B. Student Perceptions of Learning Effectiveness}

A series of student-focus groups was conducted over several semesters for the engineering degree courses, including the chemistry, calculus, and engineering case-study courses. Both the overall responses $(n=51)$ and the responses in 


\section{EDUCATIONPROGRAM}

case-study courses $(\mathrm{n}=13)$ reflect a generally favorable student perception of learning effectiveness. A large majority $(84 \%)$ of students overall felt that they had equal (74\%) or greater (10\%) access to learning resources in ELI ALN courses than in on-campus classes. An even greater majority (92\%) was satisfied with their level of access to learning resources in ELI ALN courses. Two-thirds (over 70\% in the case study courses) felt that ELI ALN courses were an equally or more effective way to learn than on-campus classes. Over $90 \%$ of student respondents said that they would take another ELI course based on their experience in the Engineering degree courses, thus indicating high overall student satisfaction.

\section{Course Grades}

As Tables 8 and 9 indicate, the case-study courses, as is generally the case with distance-learning courses everywhere, have a higher student withdrawal rate than on-campus courses; however, students who started casestudy courses have success rates comparable to their on-campus counterparts [5]. Although the grade results for the non-engineering degree courses are incomplete, results thus far indicate that these courses will have similar success rates. Course grades also reflect the typical ELI pattern (for both ALN and non-ALN courses) of polar success/failure, i.e., lots of As and Fs, some Bs, and very few Cs and Ds.

\section{Legend:}

$\mathbf{W}=$ students who withdrew from the course

NS $=$ Non-Starters $=$ students who withdrew before submitting any assignments

$\mathbf{I}=$ Incompletes $=$ students who have not yet finished their course

$\mathbf{R}=$ Refunds $=$ students who withdrew with refund before starting their course

$\mathbf{X}=$ Audited course.

\begin{tabular}{|llllllllllll|}
\hline \multicolumn{1}{r}{ Course } & A & B & C & D & F & W & NS & I & R & X & Total \\
\hline CHM 111 & 30 & 39 & 9 & 2 & 15 & 81 & 38 & 3 & 13 & 4 \\
CHM 112 & 10 & 3 & 1 & 0 & 0 & 11 & 6 & 0 & 1 & 0 & 26 \\
EGR 120 & 32 & 17 & 10 & 0 & 24 & 63 & 50 & 0 & 10 & 0 & 156 \\
MTH 277 & 15 & 16 & 12 & 9 & 5 & 44 & 22 & 7 & 5 & 1 & 114 \\
MTH 291 & 13 & 11 & 6 & 0 & 9 & 40 & 27 & 10 & 5 & 2 & 96 \\
MTH 151 & 13 & 21 & 4 & 0 & 17 & 28 & 15 & 27 & 0 & 0 & 110 \\
MTH 152 & 5 & 0 & 1 & 0 & 1 & 7 & 3 & 6 & 0 & 0 & 20 \\
IST 128 & 72 & 21 & 4 & 0 & 49 & 60 & 51 & 21 & 2 & 5 & 234 \\
Totals & $\mathbf{1 9 0}$ & $\mathbf{1 2 8}$ & $\mathbf{4 7}$ & $\mathbf{1 1}$ & $\mathbf{1 2 0}$ & $\mathbf{3 3 4}$ & $\mathbf{2 1 2}$ & $\mathbf{7 4}$ & $\mathbf{3 6}$ & $\mathbf{1 2}$ & $\mathbf{9 5 2}$ \\
\hline
\end{tabular}

Table 8. Course Grades, NVCC Case Study Courses, through Summer 1999 Semester

Table 9 also indicates comparative results for the same instructor when that same instructor taught the same course both on-campus and at ELI in the same semester. Comparison data by instructor is limited, partly because most instructors opted to drop their on-campus sections of the same course after beginning to teach or while teaching the ELI ALN versions. However, within the limited data (in the chemistry courses), it is striking how similar the results are between the ELI ALN and on-campus courses.

\begin{tabular}{|c|c|c|c|c|}
\hline Course & $\begin{array}{c}\text { ELI } \\
\text { (thru Sum'99) }\end{array}$ & $\begin{array}{c}\text { ELI } \\
\text { (thru Fall'97) }\end{array}$ & $\begin{array}{l}\text { On-Campus } \\
\text { (thru Fall'97) }\end{array}$ & $\begin{array}{c}\text { On-Campus } \\
\text { Same Instructor, Same Semester } \\
\text { (thru Sp'99) }\end{array}$ \\
\hline CHM 111 & $56.5 \% *$ & $58.9 \%$ & $64.5 \%$ & $55.7 \%(\mathrm{n}=93)$ \\
\hline CHM 112 & $73.7 \%$ & $60.0 \%$ & $53.2 \%$ & $73.9 \%(n=64)$ \\
\hline EGR 120 & $61.5 \%$ & $54.0 \%$ & $63.0 \%$ & $\mathrm{n} / \mathrm{a}$ \\
\hline MTH 277 & $54.4 \% *$ & $57.8 \%$ & $72.9 \%$ & $71.2 \%(\mathrm{n}=52)$ \\
\hline MTH 291 & $57.7 \% *$ & $77.8 \%$ & $61.8 \%$ & $\mathrm{~N} / \mathrm{A}$ \\
\hline MTH 151 & $55.9 \% *$ & $\mathrm{~N} / \mathrm{A}$ & $\mathrm{N} / \mathrm{A}$ & $\mathrm{N} / \mathrm{A}$ \\
\hline MTH 152 & $54.5 \% *$ & $\mathrm{~N} / \mathrm{A}$ & $\mathrm{N} / \mathrm{A}$ & $\mathrm{N} / \mathrm{A}$ \\
\hline IST 128 & $62.6 \% *$ & $\mathrm{~N} / \mathrm{A}$ & $\mathrm{N} / \mathrm{A}$ & $\mathrm{N} / \mathrm{A}$ \\
\hline
\end{tabular}


*Pending Spring and Summer '99 completed

Table 9. Course-by-Course ELI vs. On-Campus Starter Success Rates, Cumulative

While course performance has varied by semester, this is probably a function of the particular collection of students enrolled in a course for a given semester rather than a reflection of the courses themselves. Other data indicate that performance varies at least as greatly from semester to semester within on-campus courses as it does between oncampus and ALN ELI courses.

\section{CONCLUSIONS}

NVCC case study courses indicate that ALN courses, even those in their pioneering or early stages, can be a viable and successful way for community college students to learn. NVCC's experience with its case study and other ALN courses also support several other conclusions:

- ALN can succeed in a distance education program delivered in an independent study format and designed to provide maximum flexibility and convenience to motivated learners.

- ALN works within a multiple media approach to course and delivery; i.e., ALN courses do not have to be on-line cybercourses, but rather ALN courses that integrate various media can be delivered effectively.

- Faculty selection, support, and development are critical factors in assuring quality ALN courses, in particular because faculty are a key resource in generating best practices in course design and delivery.

- A wide variety of best practices can result in successful ALN courses, and we are just beginning to learn about what these best practices are.

- The learning effectiveness of ALN courses will continue to improve as better tools, content, and support are developed.

\section{REFERENCES}

1. Sener, J. Developing a distance education engineering program for home-based learners: Lessons learned. Journal of Instruction Delivery Systems, pp. 41-45, Winter, 1996.

2. Sener, J. Creating asynchronous learning networks in mathematics, science, and engineering courses for homebased learners. International Journal of Educational Telecommunications, Vol. 3, no. 1, pp. 23-40, 1997, http://www.aace.org/pubs/ijet/v3n1.html.

3. Goral, D. Carrots, sticks, and distance learning II: Math on the web. VCCS New Horizons Conference, Richmond, VA, April, 1999, http://elisp.nv.cc.va.us/dgnh99/index.html.

4. Lemke, R. Encouraging and supporting asynchronous learning networks. First International Conference on Asynchronous Learning Networks, Philadelphia, October, 1995, http://elisp.nv.cc.va.us/aln.html.

5. Sener, J., and Stover, M. An AS engineering degree program via ALN. Proceedings of the 1997 ASEE/IEEE Frontiers in Education Conference, Pittsburgh, PA, November, 1997.

\section{ABOUT THE AUTHORS}

John Sener is Project Director and Instructional Technologist for the Sloan-funded projects at Northern Virginia Community College's Extended Learning Institute. Over the past five years at NVCC/ELI, Mr. Sener has directed development of associate degrees in engineering, information systems technology, public management, and business management, available through home study and on-line distance education. He has been responsible for course and technology development, project evaluation coordination, marketing and publicity, budget supervision, and dissemination of project results. Mr. Sener's career in education and training over the past twenty-one years includes directing a number of foundation and federally funded projects; he has also been a trainer, teacher, administrator, instructional designer, and tutor in the areas of adult literacy, basic skills, information systems, and English as a 
Second Language. He holds a M.S. degree in Education from Johns Hopkins University and a B.A. in Psychology from Oberlin College.

Contact: Extended Learning Institute, Northern Virginia Community College, 8333 Little River Turnpike, Annandale, Virginia 22003; Telephone: 703-323-3712;Fax: 703-323-3392; E-mail: jsener@nv.cc.va.us; URL: http://elisp.nv.cc.va.us.

Mary Liana Stover is Assistant Dean for Communication, Arts, and Humanities at the University of Maryland University College. She is currently responsible for over 90 sections of ALN courses serving 4000 students in Foreign Language, English, History, and the Arts. From 1997 to 1999 Dr. Stover served as the Director of the Extended Learning Institute of Northern Virginia Community College where she worked with Sloan -funded projects to develop ALN degree programs in Engineering, Information Systems Technology, Public Management, and the Liberal Arts. An anthropologist by training, Dr. Stover has served on the faculty of the Open University in London, University of London Birkbeck College, Monterey Institute of International Studies, and the University of Hawaii.

Contact: Communication, Arts, and Humanities, Undergraduate Programs, University of Maryland University College, 3501 University Boulevard East, Adelphi, Maryland 20783; Telephone: 301-985-7877; Fax: 301-985-7910; Email: mstover@umuc.edu. 
INTEGRATING ALN INTO AN INDEPENDENT STUDY DISTANCE EDUCATION PROGRAM 


\title{
Integrating ALN Into an Independent Study Distance Education Program: NVCC Case Studies
}

\author{
John Sener and Merrily Stover
}

\section{Discussant: Linda Thompson, Northwest Technical College}

\begin{abstract}
"Integrating ALN into a Home Study Distance Education Program" authored by John Sener and Merrily Stover from Northern Virginia Community College (NVCC) is a compelling report of how a college can respond to market need with above average outcomes. NVCC is dedicated to addressing the need of adult learners in their geographic area in many ways. For this case study, the focus is on NVCC's Extended Learning Institute (ELI) Chemistry, Engineering, Mathematics and Information Systems Technology courses. They present the comparison of the outcomes as well as some unique characteristics that each of the courses presents for effectiveness. They further explore NVCC's case studies with regard to how an institution conceptualizes a course for ALN delivery through implementation and how the institution supports its student from the very onset of interest in a course to completion of a course. This paper from NVCC will clearly point out that when a thoughtful approach to student outcome is the undergirding guide in ALN delivery, students can achieve a high level of success.
\end{abstract}

The learners that NVCC's Extended Learning Institute (ELI) identified as its primary market are students who are usually employed or have outside responsibilities that create a barrier to coming on campus for coursework. These individuals are non-traditional students in that the general age group is higher and they come to ELI with a skill set from their work experience. This group will have less uninterrupted time. Therefore, it is assumed they will approach their learning in unique ways. These types of learners constitute about one-half of ELI learners. The other group are onsite learners who have a variety of constraints and find the ALN approach to learning satisfying.

As a well-known fact, society is changing. The demographics of the United States are changing. Sixty-five percent of the population is over the age of 40. The economic climate is changing as it moves into the information age. Business is becoming more global and utilizing technology, thus, the need for education becomes imperative. Sectors of the population are seeking alternatives to traditional classroom instruction due to constraints on their lives and pressures from the changing economic climate.

Education has also been experiencing a shift in how to provide education due to the new demands of the economic environment. In ALN delivery, Northwest Technical College has found in ALN courses that the average student age is higher and the percentage of our non-traditional student (those taking ALN courses only) continues to increase. Most students come with a wealth of experience that creates a more diverse learning environment. Instructor's roles are changing to facilitate and direct learning versus traditional lecture modules. Dramatic changes such as these come infrequently in history. ALN is becoming a unique alternative to a unique set of societal problems.

As NVCC is a community college, the issue of serving entry-level students does arise. There are many learners who come to ELI who hold a higher educational degree and are experienced learners. Equally, there are also entry-level students who come to ELI who are not experienced learners and have a special set of issues regarding how to become a successful distance student. Entry-level students experience issues such as anxiety over successful outcomes and if they can accomplish outcomes successfully. ELI addresses this situation quite appropriately.

Before a student registers for an ELI class he or she is encouraged to take the pre-assessment evaluation that is posted on the Web site. Once students have answered the brief, but pointed questions on the assessment, they compare their answers to an answer sheet that will help them understand if they can be a successful distance student. If there are reasons why the student may not be successful according to the answers given, there are helpful tips for potential students to see why this may not be the right delivery method for them. 
Once students have overcome their initial anxiety of entering an ALN course, they find if the course is well designed and well taught it is an exciting experience. The components that lead to this outcome are appropriate pedagogy and appropriate use of technology whereby the educational experience desired drives the choice of technology used to benefit and support the student in the best way possible. When these expectations are met, students can thrive in this learning environment and enjoy taking charge of their learning.

Many students approach ALN courses with some unique expectations. Students desire courses that are current and authoritative, flexible and accommodate a variety of learning styles, guidance on how and what to study, opportunities to do something with the knowledge they are obtaining, feedback on their work and their progress, and help working through administrative or personal issues related to the course (Moore and Kearsley, 1996).

History has shown us that many distance education courses have been developed and delivered in an unplanned fashion. This, of course, makes educators and students skeptical as they enter the distance arena. When distance courses are developed through a systems approach, then there are control mechanisms in place that lead to successful development and successful outcomes. By utilizing the expertise of a variety of individuals instead of depending on past practices of asking faculty to develop everything themselves, a richer, more comprehensive learning environment where students thrive occurs (Moore and Kearsley, 1996). ELI has taken this unique systems approach with good outcomes.

Computer technology is the method used to keep learners and instructors interacting. ELI has evolved the content delivery method from print to Web delivery in the past two years with course delivery management tools and various types of software. Different courses, however, used different media and it has evolved over time to address a variety of needs. Strategies for implementing computing technology were first field tested in the on-site classroom. When they met with success, they were folded into the ALN as part of the delivery package.

ELI uses the expertise of faculty and instructional technologist to approach development of their courses and use formative and summative evaluation to ensure quality. These types of evaluations are helpful in ensuring student success. Within the formative evaluation, the instructor can tell right away if students are able to meet the learning outcomes. If they are not meeting course outcomes, then there is time to make some changes within the course to ensure that outcomes are attained. The summative evaluation is very helpful in the course as a whole and evaluating the systems that make the course successful.

In the courses of the four subject areas that are involved in this case study from ELI, the special requirements are as diverse as the courses are themselves. For example, in the Chemistry classes one needs to write an introductory letter and a plan for completion of the course whereby in the Math courses one would need to complete assignments and quizzes and credit is given in a unique way to encourage students taking charge of their learning. Outcomes are thought through carefully in these subject areas so that when a student has completed the course successfully, the skills they learned can be used immediately in a meaningful way.

It is this mindset that makes these courses excellent cases studies for NVCC and ELI. It is within the new paradigm that ALN delivery must address outcomes in the way that adult learners can learn. Thereby, they take into account adult learners limited chunks of time to work on courses plus the experience they have gained through their own lives.

The overall results for student success through these courses, based on grades, have been comparable to NVCC's on-campus courses. It was also noted that ELI courses have a higher withdrawal rate which is standard for ALN courses for a wide variety of reasons. Students who have started their ELI courses did complete with scores comparable to NVCC's on-campus scores. 
ELI student focus groups were established over several semesters to determine student perceptions in learning effectiveness. Many students felt that they had equal or greater access to learning resources than in a traditional oncampus course. Seventy percent of students felt that ELI ALN courses were equal to or more effective than oncampus courses; $90 \%$ would take an ALN course again based upon experience in the Engineering courses.

The faculty for the case study courses attributed successes to a variety of course design and student-related factors. They determined that pedagogy and technology factors were critical for successful learner outcomes. The pedagogy and the technology factors that led to student success in each of the disciplines are different for a variety of reasons as stated above. Overall, faculty were satisfied with outcomes based upon student successes but noted that the mix of students one gets in a class also can be a defining point that leads to success or failure.

\section{ABOUT THE DISCUSSANT}

Linda Thompson is the Director of Distance Education for Northwest Technical College, a multi-campus entity located in Northwest Minnesota. She has assisted the five campus of Northwest Technical College in the development and delivery of Distance Education via the web and through correspondence for the past three years. Linda brings to this arena 13 years of experience as an educator and her academic area is in the studies of technology, management and distance education administration.

Contact: Northwest Technical College, Post Office Box 309, Perham, Minnesota 56573; Telephone: 701-795-8886, 218-347-6216; Fax: 218-347-6210; E-mail: linda.thompson@mail.ntc.mnscu.edu. 